\title{
O slam como prática de letramento na escola
}

Bruna Nathália Salermo Souza"

Fabiane Burlamaque**

Izandra Alves ${ }^{* * *}$

\section{Resumo}

A produção artística do slam se apresenta como uma prática extraordinariamente democrática, englobando as notáveis mudanças provenientes das interações sociais atuais e todas variações dela decorrentes. Uma vez que essa prática iniciou em grades centros urbanos e de certa forma se mantém assim, indica um caráter multifacetado e fluído, de forma que a maior parte dos registros desses eventos encontram-se através de narrativas dos participantes ou gravação das performances. A partir da análise desses registros e de materiais bibliográficos, nos propomos a discutir esse gênero. Considerando os conceitos de letramento literário e multiletramentos, também dissertamos sobre o afastamento juvenil da leitura, de forma a possibilitar que jovens encontrem nessa prática um espaço de protagonismo, de (re)descobertas e expressão da própria subjetividade, fazendo uso de temáticas próprias do slam ou criando suas próprias temáticas, pelas demandas apontadas a partir da própria realidade ou externas, através da escrita, oralidade e performance.

Palavras-chave: Slam; escolarização; literatura marginal; letramento literário.

\section{Introdução}

O slam tem conquistado importantes espaços de circulação tanto nas grandes como nas pequenas cidades de todo o mundo. Praças, escadarias e prédios públicos têm sido palco para os slammers soltarem sua voz e serem ouvidos.

Estar presente nos espaços de circulação pública, se fazer ver e ouvir mesmo que, por vezes, de maneira impositiva pelo fato de estar aí, entre "as gentes", o slam demonstra seu caráter inclusivo, participativo e combativo. Trata-se de um gênero discursivo e poético contemporâneo com forte expressão e manifestação da oralidade que, infelizmente, ainda se apresenta tímida no espaço escolar

* Professora de Língua Portuguesa e Literatura da rede Estadual do Rio Grande do Sul. E-mail: bnathali.souza@gmail.com

** Professora Doutora do PPGL da Universidade de Passo Fundo. E-mail: fabianevb@uol.com.br

**** Professora Doutora do Curso de Licenciatura em Letras Português e Inglês do IFRS, campus Feliz. E-mail: izandra.alves@feliz.ifrs.edu.br

Data de submissão: abr. 2021 - Data de aceite: jul. 2021 http://dx.doi.org/10.5335/rdes.v17i2.11338 
e no ensino/prática do letramento em Língua Portuguesa.

Bezerra (2010), ao analisar o ensino de Língua Portuguesa no país, aponta que é pautado na gramática normativa, seja pelo modelo prescritivo ou pelo analítico. Segundo a autora, isso deve-se a fatores internos e externos e acontece desde quando a Língua Portuguesa passou a integrar os currículos escolares. Já Aguiar (2001, p. 239) analisou o uso da literatura na escola e afirma que

[...] historicamente, a leitura está vinculada à escola, instituição responsável pela educação dos indivíduos nas sociedades modernas e, especificamente, pela alfabetização.

O que percebemos desde sempre nas escolas é que os currículos tendem a se organizar de maneira a atender somente aos discentes que correspondam a limites de uma suposta normalidade aceita pelos parâmetros sociais vigentes, de modo que muitas necessidades de alunos presentes naquele ambiente formal de educação acabam não sendo contemplados pelo currículo utilizado. Apesar das muitas discussões acerca da necessidade de adaptações e transformação dessa visão tão limitada, a escola ainda está muito ligada à perspectiva de um ensino tradicional, que muito mais exclui do que inclui os estudantes.

Nesse sentido, Aguiar (2006, p. 240) aponta que a escola tradicional "opõe-se à escola sensível à diversidade, pronta para trabalhar com realidades variadas, tal qual o mundo lá fora”. O que temos notado a partir de pesquisas relacionadas ao tema, é que essa perspectiva de escola sensível à diversidade abre espaço para que o slam se mostre como uma possibilidade de ensino.

O slam, esse gênero discursivo com aceitação tímida na escola, surgiu nos Estados Unidos em meados dos anos oitenta e, de lá para cá, tem se expandido para todo o mundo. O estudo do pesquisador Tiago Barbosa Souza (2011b) traçou o perfil histórico de surgimento do slam e sua posterior ascensão enquanto forma de livre expressão, que não possui obrigação de ater-se a padrões vigentes de literatura ou performance.

No Brasil, o slam surgiu em 2008, através da escritora e slammer Roberta Estrela D'Alva, que mostra, cada vez mais, que essa poesia está se consolidando como uma importante ferramenta de expressão. Da mesma forma, ao adentrar os espaços formais de educação, muitos educadores com visão mais inclusiva de ensino de Língua e Literatura veem esse gênero discursivo como uma possibilidade de ser ferramenta de ensino na escola.

Destacamos neste artigo que o slam é tanto utilizado para designar o gênero discursivo em si - no sentido bakhtiniano que explora a riqueza da linguagem e expressão como gênero discursivo primário (BAKHTIN, 2000), como também para referir-se às batalhas, que são os momentos em que as poesias são lidas, 
declamadas, proferidas em público e aos coletivos, que são os nomes dados aos grupos que propõe as batalhas e se organizam em torno dos textos.). Enfatizamos que na bibliografia utilizada para o presente trabalho não foram encontradas diferenciações quanto ao uso do termo, sendo ele empregado, então, para todas as etapas da batalha e ainda para a performance.

Acreditamos, e neste trabalho damos ênfase, que a prática do slam dentro da sala de aula, muito mais do que contribuir como um gênero de estudo de Língua Portuguesa e Literatura, mostra-se cada dia mais como uma forma de libertação e de voz a estudantes que são comumente excluídos ou não são acolhidos pelo sistema escolar de maneira que respeite suas individualidades e diferenças culturais e linguísticas. Dessa forma, a batalha de poesias se estabelece como um local de protagonismo a esses jovens, tão múltiplos e heterogêneos. Assim, pretendemos discutir neste trabalho, quais as possibilidades que têm a escola de promover o protagonismo de seus alunos através do slam e de que maneira ele pode ser utilizado como possibilidade de letramento literário. Para tanto, nos valemos, principalmente, dos estudos de Bordini (2003), Soares (1998, 2006), Cosson (2018), Rojo e Moura (2012) e D’Alva (2011). Utilizamo-nos de inúmeras entrevistas e páginas oficiais de slam nas redes sociais, porém, ainda é muito raro o material teórico disponível em Língua Portuguesa a fim de iniciar esta discussão do slam enquanto importante aliado do professor de Língua Portuguesa e Literatura, muito embora nem todos saibam dessa importância. Este trabalho vem, então, com o propósito de ajudar a abrir portas para esta prática de manifestação poética na escola a fim de, além de quebrar barreiras do preconceito, estabelecer conexões com os multiletramentos.

\section{Slam: muito além de um simples conceito}

Oriundo das periferias estadunidenses, o poetry slam ou simplesmente slam surge nos anos 1980 como manifestação cultural de um povo à margem de uma sociedade excludente que clama por falar, por manifestar-se, por ser protagonista de sua história. Enquanto significado literal, a palavra slam é uma onomatopeia da língua inglesa utilizada para indicar o som de uma batida de porta ou janela. A pesquisadora Cyntia Neves (2017) explica que esta palavra se aproxima do "pá!", da língua portuguesa. Ela explica que o termo foi emprestado por Marc Kelly Smith, um trabalhador da construção civil e poeta, que o utilizou para nomear o Uptown Poetry Slam, evento poético iniciado por ele em 1984, na cidade de Chicago. A pesquisadora (NEVES, 2017) menciona, ainda, que o 
termo slam também é empregado para se referir às finais de torneios de baseball, tênis, bridge, basquete, por exemplo. Marc Kelly Smith, aproveitou o mesmo termo para nomear também os campeonatos de performances poéticas que organizava. Nas disputas, os slammers (poetas) eram avaliados com notas pelo público presente, sendo que os encontros ocorriam, inicialmente, em um bar de jazz em Chicago e, depois, espalharam-se para as periferias da cidade. A iniciativa se difundiu, contagiando outras cidades dos Estados Unidos e, mais tarde, ganhou o mundo.

Pela ampla divulgação e propagação do slam nos centros urbanos e, quase sempre, tendo minorias como grupo participante, percebemos sua estreita relação com diferentes atividades de interação social próprio desses ambientes e tribos, como o Hip-Hop, por exemplo, e embora se concretize de maneira diferente, possui bases muito semelhantes. Nesse sentido, a escritora e também slammer, Roberta Estrala D'Alva, afirma que

Poderíamos definir o poetry slam, ou simplesmente slam, de diversas maneiras: uma competição de poesia falada, um espaço para livre expressão poética, uma ágora onde questões da atualidade são debatidas ou até mesmo mais uma forma de entretenimento. De fato, é difícil defini-lo de maneira tão simplificada, pois, em seus 25 anos de existência, ele se tornou, além de um acontecimento poético, um movimento social, cultural, artístico que se expande progressivamente e é celebrado em comunidades em todo mundo. (D'ALVA, 2011, p. 109).
Por seu caráter participativo e interativo e que se propõe a dialogar com todos os públicos, tanto os que dominam e empregam a palavra de maneira mais "intelectualizada", como aqueles que a utilizam como expressão de suas vivências diárias e sentimentos mais íntimos, o slam é uma competição de poesia falada que acontece, na maioria das vezes, em espaços públicos, tais quais praças e parques a fim de atingir a todos. Há situações em que o slam acontece em lugares fechados, como casas de culturas, bares, escolas e universidades, havendo ainda alguns slams itinerantes, que não possuem local ou datas específicas e, podem, ainda, acontecer separadamente, cada etapa da competição em um local diferente.

Podemos notar, então, que encontrar definições específicas e fechadas a respeito desse tema se constitui uma tarefa das mais complexas. Sabemos, contudo, das características de sua proposta de se construir como espaço aberto, livre e democrático, onde questões atuais podem vir à tona pelas vozes dos slamers. Temas que podem explorar desde a política até questões de gênero que são debatidas de modo a constituir-se como momentos de desenfado, sem deixar de lado o posicionamento e atitude críticos.

Em todas as competições, há uma estrutura básica, embora possa receber alterações de acordo com as características de cada evento. Para apresentar-se, 
o poeta tem até três minutos e seu texto pode ser autoral ou não, a depender das regras daquele determinado slam. Quanto à escrita, pode ser prévia ou não, sendo que não há regras a respeito do formato da poesia. Para cada uma das fases da competição é necessária uma poesia original, sendo obrigatórias entre duas e três poesias por evento.

Consideramos relevante mencionar a relação que existe entre o slam e a noção de coletividade. Dizemos isso porque o slam só se constitui durante o contato com o outro. Nas competições a resposta é imediata e isso é de extrema importância para a caracterização e continuidade das atividades. Como explica D'Alva, não há como construir uma proposta de coletividade no slam sem o envolvimento do grupo.

Para que um slam aconteça é fundamental a participação coletiva e ativa de todos os presentes e, embora existam artistas que se destaquem na cena, até mesmo tornando-se celebridades e seguindo carreiras solo, como é o caso de Saul Williams, ator do premiado filme Slam (Levin, 1998), estes são considerados por muitos slammers como artistas que fazem spoken word, e não slam, na medida em que este último só se dá com a participação da comunidade, de outros slammers, sem que nenhuma das partes participantes se sobreponha à outra. (D'ALVA, 2011, p. 121).

Assim, com a proposta da construção do slam enquanto representação coletiva poética, os competidores recebem notas de 0 a 10 dos jurados, mas durante todo o processo estão sujeitos a avaliação e aprovação, ou não, por parte da plateia. O envolvimento do público ocorre através de aplausos, marcações ou até mesmo vaias no caso de algum slammer fazer má utilização do espaço público e das normas do evento, como por exemplo, utilizar-se de um vocabulário inadequado para determinado público.

É dessa mesma plateia que saem os jurados, que se voluntariam no início do evento e seguem até a última etapa. A eles é solicitado que deem a nota da forma mais quebrada possível (com décimos), evitando assim uma necessidade de desempate. Os jurados se voluntariam durante o primeiro momento do "verso livre", em que os participantes - competidores ou não - podem recitar seus versos de forma livre, sem necessidade de seguir um tempo específico e sem o caráter competitivo.

\section{Slam como prática de letramento e multiletramentos}

Ao tratar do slam como uma forma de ruptura, não se pode fugir da responsabilidade de, também, adentrar o universo da escrita. Esta, por sua vez, enfrenta o obstáculo da superação do analfabetismo. Como sabemos, entre as minorias, o índice de analfabetos é maior. Assim, o alcance de envolvimento como poeta/ slammer é menor. 
Nesse sentido, faz-se necessário trazer presente o conceito de analfabeto defendido por Soares (1998), que afirma ela que analfabeto não é somente aquele que não dispõe das tecnologias do ler e do escrever, mas aquele que não pode exercer os direitos de cidadão, que é marginalizado pela sociedade, que não tem acesso aos bens culturais. Esse estado de analfabeto chama-se analfabetismo. Assim, surgiu nos últimos anos uma nova demanda, a de quem sabe ler e escrever, mas não sabe fazer uso disso, não responde às exigências da leitura $\mathrm{e}$ da escrita que a sociedade faz continuamente. Por isso, surgiu a necessidade de buscar/criar um termo que abarque este significado: eis o letramento.

Segundo Soares (1998), o termo letramento é a versão para o português da palavra da língua inglesa literacy, que significa o estado ou condição que assume aquele que aprende a ler e escrever. Significa dizer, então, que é muito mais do que o resultado da ação de ensinar ou de aprender a ler e escrever, ou sim, o estado ou condição que adquire um grupo social ou um indivíduo como consequência de ter-se apropriado da escrita. Ela ainda aponta que a palavra letramento, assim como o seu conceito, é algo recente no Brasil; foi introduzido na área da educação há pouco mais de duas décadas; seu surgimento deu-se pela necessidade de configurar e nomear comportamentos e práticas sociais na área da leitura e da escrita que vão além o domínio do sistema alfabético e ortográfico.

O que percebemos é que à medida em que a vida social e as atividades profissionais tornaram-se cada vez mais ligadas e dependentes da língua escrita, práticas mais sociais de leitura e escrita acabaram por adquirirem visibilidade. Já não basta alfabetizar - tradicionalmente uma preocupação com codificação e decodificação de códigos linguísticos, é preciso que essas práticas de leitura $\mathrm{e}$ escrita estabeleçam alguma ação concreta ou tenham significação no mundo do alfabetizado; nesse contexto, a alfabetização que se preocupava simplesmente com a decodificação da letra/palavra tornou-se insuficiente. É dessa maneira que a pessoa letrada muda seu lugar social, seu modo de viver na sociedade, sua inserção na cultura, sua relação com os outros, com o contexto e com os bens culturais. $\mathrm{O}$ uso da língua escrita muda a forma de usar a linguagem oral.

Mesmo que no Brasil o letramento e a alfabetização não sejam tratados como sinônimos, é comum que o termo letramento apareça interligado ao conceito de alfabetização. Com o intuito de aclarar possíveis confusões com a terminologia, Soares (2006) distingue-os, sinalizando ainda que o uso do termo letramento não anule as especificidades que envolvem o processo de alfabetização. Segundo a autora, 
Embora correndo o risco de uma excessiva simplificação, pode-se dizer que a inserção no mundo da escrita se dá por meio da aquisição de uma tecnologia - a isso se chama alfabetização, e por meio do desenvolvimento de competências (habilidades, conhecimentos, atitudes) de uso efetivo dessa tecnologia em práticas sociais que envolvem a língua escrita - a isso se chama letramento. (SOARES, 2006, p. 90).

Notamos que o letramento vai além do conceito de alfabetização; ele completa uma ideia de prática social, que engloba dois diferentes fenômenos: leitura e escrita. Assim, a autora complementa, dizendo que o "letramento é o que as pessoas fazem com as habilidades de leitura e escrita, em um contexto específico, e como essas habilidades se relacionam com as necessidades, valores e práticas sociais" (SOARES, 2014, p. 72). No caso do slam, essas habilidades são usadas em um contexto onde o slamer dialoga com a plateia, expondo suas necessidades e a de quem o escuta/avalia; ao ganhar voz, assume o papel de protagonista pois, na maioria das vezes, não é ouvido em suas reivindicações habituais. Através das batalhas, então, os slamers expõem como são capazes de articular suas práticas sociais e valores culturais através da palavra falada.

Nesse sentido, o que determina o letramento é a capacidade de articulação que faz o leitor com aquilo que lê e suas vivências e valores sociais. Assim, é possível que alguém seja capaz de ler um bilhete e não demonstre a mesma ca- pacidade ao ler uma revista, compreenda uma mensagem escrita nas redes sociais, mas não uma crônica. A prática do letramento não é homogênea, pois

[...] há diferentes tipos e níveis de letramento, dependendo das necessidades, das demandas do indivíduo e de seu meio, do contexto social e cultural (SOARES, 2014, p. 48-49).

Ao se tratar de slam, no entanto, os conceitos de alfabetização e letramentos tornam-se insuficientes na medida em que ambos não dão conta de acompanhar a multiplicidade de linguagens, modos ou semioses nos textos que são produzidos e estão em circulação, independente da mídia social que ele esteja inserido. Assim, faz-se necessário a abordagem do conceito que Rojo e Moura (2012) nos dá acerca do multiletramentos. A autora

\begin{abstract}
aponta para dois tipos específicos e importantes de multiplicidade presentes em nossa sociedade, principalmente urbanas, na contemporaneidade: a multiplicidade cultural das produções e a multiplicidade semiótica de constituição dos textos por meio dos quais ela se informa e se comunica. (ROJO; MOURA, 2012, p. 13)
\end{abstract}

Segundo a autora, entra em jogo, no multiletramentos, outros fatores importantes, principalmente, no que se refere à constituição dos textos. Então, não é só a capacidade de decifrar um código qualquer, mas o modo de apresentação desse código faz a diferença para a compreensão e o domínio. Assim, notamos a 
necessidade de englobar, aqui, o conceito de letramento literário, que se preocupa em apontar a multiplicidade e variedades das práticas letradas, sejam elas valorizadas ou não dentro da sociedade. Notamos, então, que o conceito de multiletramentos é mais amplo e engloba o particular e o social da língua e de suas produções.

Quanto à origem ou ao uso primeiro do termo multiletramentos, sabe-se que foi empregado em 1996, pelo Grupo de Nova Londres. Sua afirmação enquanto teoria ocorreu em um manifesto resultante de um colóquio e, desde sua concepção, buscou elucidar o que seria uma educação linguística adequada a alunos multiculturais. A proposta mostra-se tão abrangente quanto, de certo modo, inclusiva. Isso porque,

na contemporaneidade, uma educação linguística adequada a um alunado multicultural se configura, segundo a proposta, como aquela que possa trazer aos alunos projetos (designs) de futuro que considerem três dimensões: a diversidade produtiva (no âmbito do trabalho), o pluralismo cívico (no âmbito da cidadania) e as identidades multifacetadas (no âmbito da vida pessoal). (ROJO; MOURA, 2012 p. 14).

Partimos desse conceito de multiletramentos para analisarmos o slam como um texto que se constitui com características multimodais e multifacetadas e, por possuir esta particularidade, rompe com os conhecimentos tidos como escolarizados. Esse rompimento acontece, porque os slams trazem em sua constituição, imagens subliminares e arranjos muito particulares que impregnam e fazem significar os textos contemporâneos, não mais ligados estritamente à escrita. A compreensão desses textos exige multiletramentos, isto é, o slam é um gênero discursivo que se constrói a partir

[...] de muitas linguagens (ou modos, ou semioses) e que exigem capacidades e práticas de compreensão e produção de cada uma delas (multiletramentos) para fazer significar (ROJO, MOURA; 2012 p. 19).

Por conta do surgimento desse gênero ainda tão novo no meio escolar, também o conceito de multiletramentos está em construção. No entanto, os resultados desses estudos são unânimes em apontar algumas características importantes: eles são interativos e colaborativos; são híbridos, mestiços (de linguagens, modos, mídias e culturas) e, por fim,

[...] fraturam e transgridem as relações de poder estabelecidas, em especial as relações de poder de propriedade (das máquinas, das ferramentas, das ideias, dos textos [verbais ou não]) (ROJO; MOURA, 2012, p. 23).

O fato de os jovens viverem concomitantemente entre várias culturas, faz com que tenham uma identidade multifacetada e singular, e suas produções levam em conta tanto as práticas educativas compartilhadas em ambiente escolar quanto aquelas produzidas fora do ambiente escolar, dentro da esfera cotidiana, contribuindo para que possam 
ressignificar-se. Por vezes, as manifestações artísticas oriundas de seu meio fortalecem seus laços com seus mundos e com os seus, destacando objetivos coletivos comuns. Essa característica que considera a individualidade/particularidade desses sujeitos possibilita a maior inclusão deles no mundo das letras.

Souza (2011a), ao escrever sobre a cultura hip-hop, menciona que esta manifestação artística sempre esteve intimamente ligada à prática do slam. Ela descreve o processo mencionando que os ativistas desse movimento desempenham papel histórico, social e político ao incorporar, criar, ressignificar e reinventar os usos sociais da linguagem, pois é uma maneira de inserir a palavra contestadora de forma oralizada/ declamada no contexto e para aqueles que (re)conhecem suas falas. Esses são os valores e intenções que ela chamou de letramentos de (re)existência.

\section{A escolarização da literatura, o slam e o letramento}

A escola é, em sua essência, uma instituição organizada através da diferença. Os alunos são divididos por idade, por séries, muitas vezes são divididas as turmas mais fracas daquelas que se entende por mais fortes, por classes sociais - afinal, é inegável que existe uma escola para pobre e uma escola para ricos - e, algumas escolas mais conservadoras, em pleno século XXI, conseguem manter a separação por gênero. Sendo assim, não causa espanto que a mesma fragmentação se estenda para o ensino por ela oferecido.

Somos sabedores dos inúmeros desajustes que o currículo escolar apresenta, na atualidade, no que diz respeito à adequação de conteúdos à realidade $\mathrm{e}$ interesse de seus alunos, os que são (ou deveriam ser) os verdadeiros protagonistas do aprender. Nesse sentido, Soares (2014, p. 85) aponta que "a estreita relação entre letramento e escolarização controla mais do que expande o conceito de letramento, e seus efeitos sobre a avaliação e medição do letramento são significativos [...]", isto é, a relação entre letramento e escolarização nem sempre é pacífica. Isso porque a escola, com suas regras, normas e conceitos pré-definidos não aceita os diferentes saberes de seus alunos, excluindo-os, então, do grupo dos letrados do sistema escolar.

O que salta aos olhos ao nos referirmos à leitura, à escrita, à interpretação e ao uso da oralidade letrada, que são os saberes ditos escolarizados, é que os frequentadores desse sistema não são considerados pela escola como usuários autônomos da língua escrita, pois não dominam às normas e às regras por ela estabelecidos. Contudo, fora da escola, 
[...] existem situações outras - ainda que nem sempre reconhecidas ou autorizadas que se realizam nas mais diversas esferas de atividade: a casa, a rua, o trabalho, a religiosidade (SOUZA, 2011, p. 36).

Esses espaços tomam diferentes contornos de captar e engajar sujeitos ou grupos sociais. Todos esses motivos fazem com que os letramentos empregados nessas atividades sejam múltiplos e críticos, adaptando seu uso o tanto quanto for necessário para adaptar-se ao contexto da prática.

De acordo com nossa experiência enquanto educadoras, percebemos que a escola tradicional possibilita pouca abertura para a expressão das individualidades no ambiente escolar. Os gostos e os referenciais culturais dos adolescentes, na maioria das vezes, são sufocados pelo programa curricular que é imposto pelo sistema educacional. Nesse sentido, oportunizar o conhecimento e a prática do slam dentro da sala de aula pode trazer à baila um embate entre vozes que clamam por serem ouvidas e aquelas que sempre foram, de modo que é inevitável o abalar das estruturas escolares como um todo.

As diferentes práticas de letramentos advindas dos movimentos culturais urbanos - tais quais o slam, o hip-hop, o rap - atribuem diferentes valores aos usos e sentidos da leitura e escrita, promovendo uma desacomodação de saberes que não estão mais ligados unicamente aos ambientes formais da educação. Nesse sentido, a escola, na maioria das vezes, não acolhe nem aceita esses saberes como pertencentes ao seu meio.

Acreditamos que a escola possa abrir espaço para o estudo do gênero slam, a partir de uma metodologia que respeite a constituição dessa prática enquanto livre manifestação de discursos e expressão e torne-a uma ferramenta que auxilie os alunos a descobrirem e ouvirem as próprias vozes e também daqueles que os cercam, através da produção, participação e performance, uma vez que o slam constitui-se como pluralidade e multiplicidade de vozes, em locais onde as manifestações literárias, na maioria das vezes, são deixadas de lado.

Assim, discutir acerca do slam na escola é uma possibilidade real e, por que não dizer, necessária, já que se constrói como uma ferramenta histórico-cultural, que rompe com a estrutura literária da escola tradicional e que se vale da linguagem para expressar o discurso que é próprio daqueles alunos marginalizados e preteridos pela atual escola. Uma vez que nas batalhas de poesia é o público que de forma imediata discute os textos apresentados, não é necessário que os alunos performem para que sejam de alguma forma representados, pois no slam, a plateia é sujeito ativo no processo de batalha.

Como o slam chegou ao Brasil somente em 2008 e, de lá para cá, foi se 
firmando timidamente, há espaços onde, ainda, sua interação ou não acontece ou é quase inexistente; a escola é um deles. Isso ocorre, talvez, pelo fato de que essa prática da palavra oralizada possa não atender as demandas da escola tradicional, assim, está fazendo seu caminho das ruas para os espaços formais de forma lenta e gradual.

Uma das pontes para o acesso desse gênero nas escolas é a literatura. A palavra usada em sua forma de arte poética de linguagem, quando trabalhada nos espaços escolares não somente como forma de periodização ou como cumprimento de lista obrigatória de livros para vestibulares, pode adquirir força libertadora de tantas vozes ali contidas. Ela abre possibilidades para que as diferentes práticas culturais ganhem lugar neste espaço do saber normatizado.

Mesmo que priorize a ordem e a disciplina, que procure padronizar os que a frequentam, a escola é, inegavelmente, um ambiente pautado pelas diferenças, $\mathrm{e}$ isso acontece com os conhecimentos. No que diz respeito à Literatura, por exemplo, a grade curricular insiste em despejar autores e obras que nem sempre vão ao encontro dos gostos e dos desejos de leitura dos adolescentes do século XXI. E o professor, entre o dever de cumprir o currículo e o desejo de que seus alunos se tornem leitores, por muitas vezes, não sabe como agir, e cede ao sistema.
No que se refere aos estudos da literatura como prática escolar, o pesquisador Rildo Cosson sinaliza que a literatura e a educação não possuem uma relação pacífica e enfrenta um de seus piores momentos, uma vez que segundo ele "para muitos professores e estudiosos da área de Letras, a literatura só se mantém na escola por força da tradição e da inércia curricular" (COSSON, 2018, p. 20). Para compreender como essa fragmentação e mesmo a negação da importância da literatura na sala de aula influenciam a formação - ou a não formação - do aluno leitor/escritor, é necessário compreender por que ela ocorre.

No livro Era uma vez... na escola, a professora Vera Teixeira de Aguiar (2001) aponta que, à medida em que a escolarização se espalhou pelo país, as escolas - entende-se que com a ampliação do acesso à escola também houve um aumento no número de sujeitos alfabetizados e letrados - passaram a ter mais acesso aos livros literários infantis e juvenis. Porém, menciona, ainda, a pesquisadora Aguiar, que a literatura nem sempre contribuiu para a emancipação desses jovens leitores e, em sua maioria, transformou-se em produto de consumo, perdendo seu sentido crítico e emancipador de sujeitos.

Quando se trata da alfabetização, iniciada no Ensino Fundamental, Cosson (2018) aponta que nessa etapa de ensino, o conceito de literatura torna-se 
extremamente amplo e subordinado aos interesses do ambiente escolar. Isso porque

[...] a literatura tem um sentido tão extenso que engloba qualquer texto que apresente parentesco com ficção ou poesia. O limite, na verdade, não é dado por esse parentesco, mas sim pela temática e pela linguagem: ambas devem ser compatíveis com os interesses da criança, do professor e da escola, preferencialmente na ordem inversa. (COSSON, 2018, p. 21).

Já no Ensino Médio, no entanto, o ensino de Literatura fica limitado à literatura brasileira e ainda tendo que dar conta de um programa fragmentado em períodos puramente historiográficos e ultrapassados. Assim, Cosson (2018, p. 21) afirma que

[...] usualmente em sua forma mais indigente, quase apenas como uma cronologia literária, em uma sucessão dicotômica entre estilos de época, cânone e dados biográficos dos autores.

A disciplina de Literatura ocupa uma carga horária de, normalmente, um período por semana e

[...] são aulas essencialmente informativas nas quais abundam dados sobre autores, características de escolas e obras, em uma organização tão impecável quanto incompreensível aos alunos (COSSON, 2018. p. 22).

Nesse contexto, raras são as oportunidades da leitura de um texto integral ou mesmo de uma leitura que vise unicamente o prazer e não algum conteúdo específico.
Essas críticas ao ensino de Literatura não estão ligadas ao ensinar literário, mas à forma como isso tem sido feito. Como aponta Soares (2006), é inevitável que a literatura seja escolarizada dentro das escolas, isso é a essência da escola, o escolarizar, transformar os conhecimentos de fora dos ambientes formais de educação em saberes organizados didaticamente.

Portanto, não há como evitar que a literatura, qualquer literatura, não só a literatura infantil e juvenil, ao se tornar 'saber escolar', se escolarize e não se pode atribuir, em tese, [...] conotação pejorativa a essa escolarização, inevitável e necessária; não se pode criticá-la, ou negá-la, porque isso significaria negar a própria escola. (SOARES, 2006, p. 21. Grifo do autor)

Ao longo de todo o percurso escolar, que acompanha o processo de desenvolvimento do sujeito, o que se pode notar é que o saber escolar - inclui-se aqui o saber literário - sempre esteve e está cada vez mais distante da realidade dos alunos. Isso porque sua participação na escolha dos textos, por exemplo, é quase sempre nula. Seus gostos praticamente são negligenciados e nunca contemplados. Dessa forma, os saberes da escola e os saberes dos alunos estão muito distanciados.

Os textos literários, "quando comparecem, são fragmentos e servem prioritariamente para comprovar as características dos períodos literários antes estudados" (COSSON, 2018, p. 
22). Esses textos apresentam-se ainda "sob forma de fragmentos que devem ser lidos, compreendidos, interpretados" (SOARES, 2006, p. 25). A seleção desses fragmentos está ligada aos fatores de seleção das obras que serão utilizadas para determinados fins. Assim, fragmentados e distantes dos interesses de leitura dos jovens, não cumprem com sua função criativa e interpretativa, sem falar em sua função de desalienação.

Nesse contexto, não é incomum que os professores optem por seguir o livro didático por inúmeros motivos, que vão desde a sobrecarga de trabalhos e turmas até a desmotivação por conta das políticas públicas voltadas à educação. Assim, faz-se necessário dar atenção aos textos que nele se encontram, pois, em sua maioria, são escritos para atender a determinados interesses pedagógicos. Soares (2006) denominou esses textos como pseudotextos, fragmentos que muitas vezes não são realmente textos, uma vez que não há nem mesmo uma preocupação em constituir uma sequência de frases com sentido e no final aquela literatura sirva apenas para explicitar algum conteúdo gramatical.

É importante salientar, entretanto, que não se trata de um ler por ler, é necessária sim uma sistematização da leitura literária. Como já apontado, a escolarização da literatura é inevitável, pois não há como não escolarizar algo que ocorre e se desenvolve dentro do ambiente escolar, o que acontece, no entanto, é que esse processo se dá de maneira inadequada.

A leitura literária na escola acaba sendo guiada ou pelo livro didático - que como já foi apontado, quase sempre faz uma didatização errônea do texto literário, pelos cânones muitas vezes não lidos nem mesmo pelo professor e até mesmo pela moda, decidida e influenciada pelas editoras.

Contrariamente, como exemplo bem sucedido de uma prática literária alinha aos interesses dos estudantes, queremos citar o pioneirismo do slam Altino, que é um dos coletivos de slams escolares participantes do slam interescolar, que ocorre entre escolas de São Paulo. Em matéria produzida pelo repórter Filipe Gonçalves, para o portal G1 do Grupo Globo, os idealizadores explicam todo o processo de criação e consolidação do coletivo dentro da escola. A professora Carolina Lobrigato Silva, professora de Língua Portuguesa no Ensino Médio de escola pública de São Paulo, destaca as mudanças ocorridas na sala de aula e também sobre como cada aluno vivenciou, a seu tempo, a experiência de protagonismo juvenil. Segundo ela, "o maior impacto do projeto é ver a autonomia deles, ver como eles foram crescendo com o projeto. É aquela situação que parece que se der asas eles voam mesmo. Eles querem ser ouvidos e ouvir" (GONÇALVES, 2019, s.p.). 


\section{Considerações finais}

É notável a grande mudança que houve nas interações sociais nas últimas décadas. Tais transformações ocorrem, dentre outros motivos, por conta dos avanços tecnológicos. As variações ocorrem, também, na forma em que as interações acontecem; os contatos são muito mais virtuais do que reais, ou seja, as chamadas redes sociais e outras plataformas permitem a comunicação instantânea, cada vez mais mutável e efêmera. A partir desta realidade, constata-se que é inevitável que a relação dos leitores/escritores com os textos sejam orais ou escritos - mude. É devido à multimodalidade apresentada pelos textos contemporâneos que o conceito de multiletramentos se faz necessário ao estudo do slam enquanto prática, também, pedagógica.

O que fizeram, então, leitores/escritores é reconstruir o caminho entre si e a literatura através de uma nova perspectiva e não apenas através da escola, o que não era possível há alguns anos. Na era digital, os hipertextos e as hipermídias possibilitam uma forma de interação diferenciada, instantânea e multimodal, que acaba por desafiar as práticas escolares de leitura e escrita, que mesmo antes já eram restritas e insuficientes.

É através dessa aproximação física e verbal que os leitores/escritores do slam se apresentam: seja como slammer ou como parte da plateia, todos os sujeitos envolvidos na performance poética são de alguma forma tocados por ela. Mesmo aqueles que acessam as gravações dos slams através das plataformas digitais, na atual era da informação e dos hipertextos, são parte do embate poético, dão retornos e se posicionam frente ao que foi dito, marcando sua presença de algum modo.

Ao longo desta discussão, as teorias que aqui trouxemos, nos apontam que são os leitores os que direcionam a produção literária através do diálogo que estabelecem com as obras, e não o contrário. Assim, então, são os slammer, que são ao mesmo tempo plateia e performer, leitor e escritor, encontram nesses espaços poéticos a possibilidade de (re)encontrar-se, de estabelecer-se enquanto sujeitos. Então, por que não propiciar que este encontro se dê no espaço escolar?

O exemplo do slam Altino e tantos outros coletivos, também participantes do já citado slam interescolar de São Paulo, indicam uma possibilidade real de encontro entre teoria e prática, entre o currículo escolar e os anseios de protagonismo dos estudantes.

Assim, notamos que o uso do slam em sala de aula e também fora dela afirma cada vez mais esse gênero como uma poesia performática que oportuniza, a quem dela participa, um lugar de fala, de 
descoberta, de ouvir e ser ouvido. O que passamos a ver, então, é que a poesia não está mais limitada à pura apreciação, limitada à academia e fora do alcance da população em geral. A palavra em sua expressão poética proferida pelo slam é, então, uma perspectiva libertadora e acessível. A escola apresenta-se, então, como um espaço aberto que tem na poesia, não mais a apreciação do puramente estético e da apreciação, mas sim, uma aliada para o protagonismo juvenil.

\section{Slam as a literacy practice in school}

\section{Abstract}

The artistic production of slam has presented itself as an extraordinarily democratic practice, encompassing the notable changes arising from current social interactions and all variations that have resulted from it. Since this practice started in urban centers and remains like that, it indicates a multifaceted and fluid character, so that most of the records of these events are found through the participants' narratives or recordings. From the analysis of these records and bibliographic materials, we propose to discuss this genre. Considering the concepts of literary literacy and multi-literacy, we also talk about the youth's distance from reading, in order to enable young people to find in this practice a space of protagonism, of (re)discoveries and expression of their own subjectivity, making use of themes specific to slam or creating their own themes, by the demands pointed out from the reality itself or from outside, through writing, orality and performance.

Keywords: Slam; schooling; marginal literature; literary literacy

\section{Referências}

AGUIAR, Vera Teixeira de (Coord.). Era uma vez... na escola: formando educadores para formar leitores. Belo Horizonte: Formato Editorial, 2006.

BAKHTIN, Mikhail. Estética da criação verbal. Trad. Maria Ermantina Galvão. 3.ed. São Paulo: Martins Fontes, 2000.

BEZERRA, Maria Auxiliadora. Ensino de língua portuguesa e contextos teórico-metodológicos. In: DIONÍSIO, Angela Paiva; MACHADO, Anna Raquel; BEZERRA, Maria Auxiliadora. (Org.). Gêneros textuais \& ensino. São Paulo: Parábola Editorial, 2010.

BORDINI, Maria da Glória. A poesia e seus usos na infância. In: BARBOSA, Márcia Helena Saldanha; BECKER, Paulo (Orgs). Questões de literatura. Passo Fundo: UPF Editora, 2003. p. 64 a 87.

COSSON, Rildo. Letramento literário: teoria e prática 2. ed. São Paulo: Contexto, 2018.

D'ALVA, Roberta Estrela. Um microfone na mão e uma ideia na cabeça - o poetry slam entra em cena. Pontifícia Universidade de São Paulo, São Paulo, Synergies Brésil, n. 9, 2011, p. 119- 126.

GONÇALVES, Filipe. 'Diário de Escola': Professora adota o slam para ensinar português em escola da Zona Leste de SP. G1, 2019. Disponível em: <https://g1.globo.com/ sp/sao-paulo/educacao/noticia/2019/09/30/ diario-de-escola-professora-adota-o-slam-para-ensinar-portugues-em-escola-da-zona-leste-de-sp.ghtml?fbclid=IwAR0QQk4V_cy1XSITQZs8XIPqKnThllaBKIBu0Nvw62Yg- 
TEhX9nWSXYgmppg>. Acesso em: $27 \mathrm{de}$ out. de 2019.

ROJO, Roxane Helena Rodrigues; MOURA, Eduardo (Orgs.). Multiletramentos na escola. São Paulo: Parábola Editorial, 2012.

SOARES, Magda. Letramento: um tema em três gêneros. Belo Horizonte: Autêntica, 1998.

. Alfabetização e Letramento. São Paulo: Contexto. 2006.

. Letramento: um tema em três gêneros. 3. ed. Belo Horizonte: Autêntica Editora, 2014.

SOUZA, Ana Lúcia Silva. Letramentos de reexistência: poesia, grafite, música, dança: HIP-HOP. São Paulo: Parábola Editorial, 2011a.

SOUZA, Tiago Barbosa. A performance na cantoria nordestina e no slam. Universidade Federal do Ceará, 2011. 137f. - Dissertação (Mestrado) - Universidade Federal do Ceará, Programa de Pós-graduação em Letras, Fortaleza (CE), 2011. Disponível em: <http://www.repositorio.ufc.br/bitstream/ riufc/9206/1/2011_dis_tbsouza.pdf> Acesso em 09 de set. de 2019 . 